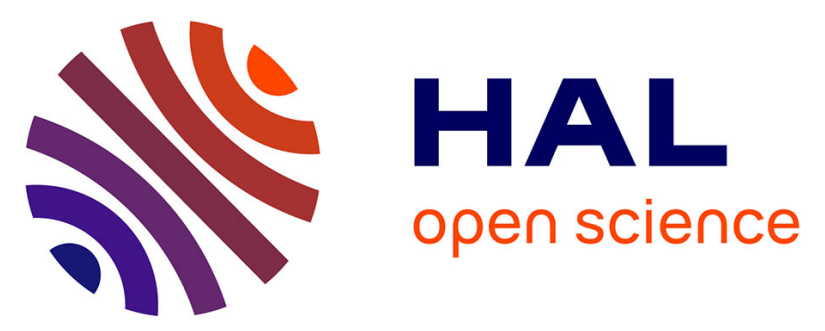

\title{
Performance Assessment for Rock Climbers: The International Rock Climbing Research Association Sport-Specific Test Battery
}

Nick Draper, David Giles, Nicola Taylor, Laurent Vigouroux, Vanesa Españ A-Romero, Jiří Baláš, Ignacio Solar Altamirano, Franziska Mally, Ina Beeretz, Jorge Couceiro Canalejo, et al.

\section{To cite this version:}

Nick Draper, David Giles, Nicola Taylor, Laurent Vigouroux, Vanesa Españ A-Romero, et al.. Performance Assessment for Rock Climbers: The International Rock Climbing Research Association Sport-Specific Test Battery. International Journal of Sports Physiology and Performance, 2021, 16 (9), pp.1242-1252. 10.1123/ijspp.2020-0672 . hal-03545303

\section{HAL Id: hal-03545303 https://hal.science/hal-03545303}

Submitted on 27 Jan 2022

HAL is a multi-disciplinary open access archive for the deposit and dissemination of scientific research documents, whether they are published or not. The documents may come from teaching and research institutions in France or abroad, or from public or private research centers.
L'archive ouverte pluridisciplinaire $\mathbf{H A L}$, est destinée au dépôt et à la diffusion de documents scientifiques de niveau recherche, publiés ou non, émanant des établissements d'enseignement et de recherche français ou étrangers, des laboratoires publics ou privés. 


\title{
Performance Assessment for Rock Climbers: The International Rock Climbing Research Association Sport-Specific Test Battery
}

\author{
Nick Draper, David Giles, Nicola Taylor, Laurent Vigouroux, Vanesa España-Romero, Jiří Baláš, \\ Ignacio Solar Altamirano, Franziska Mally, Ina Beeretz, Jorge Couceiro Canalejo, Gabriel Josseron, \\ Jan Kodejška, María José Arias Téllez, and German Gallo Cabeza de Vaca
}

\begin{abstract}
Purpose: To examine the validity and reliability of a battery of 10 measures designed to assess the key physiological parameters for successful rock climbing performance. Methods: In phase 1 of the research, an expert panel, using the Delphi method, established a 10-item test battery based on the key determinants of climbing performance. In phase 2, the tests were assessed for validity and reliability to examine their suitability as sport-specific measures of rock climbing performance. A total of 132 rock climbers, from 7 countries, volunteered to take part in the study. Each climber visited their nearest laboratory on 3 separate occasions in order to enable the required tests and retests to be completed. A minimum of 7 days was allowed between visits. Results: The 10 tests established for phase 2 were designed as sport-specific measures of flexibility, strength, power, and endurance. Results indicated that, while reliable, the flexibility and strength tests were only partially successful in differentiating across climber abilities. The power and endurance tests, however, performed well with regard to validity and reliability, with the finger hang and powerslap tests being most strongly correlated with performance ability $(P<.0005$ to $P<.002)$. Conclusion: The authors' data suggest that climbing may require a threshold level of flexibility and strength for successful performance, beyond which further improvements may not be required. In contrast, the finger hang and powerslap tests were not only reliable measures but also differentiated between climber abilities from lower grade to elite levels.
\end{abstract}

Keywords: endurance, flexibility, power, strength, successful rock climbing

Rock climbing is an increasingly popular sport with a growing research database, particularly since its inclusion in the Olympic program for Tokyo $2021 .^{1-3}$ The sport of rock climbing actually consists of a number of different disciplines including sport (lead) climbing, bouldering, speed climbing (which are the Olympic formats), deep-water solo, traditional climbing, ice climbing, and mixed climbing. While there is an increasing depth of research in the field, there has been a lack of consistency in reporting studies and also in the use of performance tests; specifically, there has been a lack of sport-specific tests that have been assessed for validity and reliability. ${ }^{4}$

Rock climbing is a demanding sport requiring psychological, skill-related, and physiological components for successful

Draper is with the School of Health Sciences, University of Canterbury, Christchurch, New Zealand. Giles is with Research and Product Development, Lattice Training, United Kingdom. Taylor is with the Human Sciences Research Centre, University of Derby, Derby, United Kingdom. Vigouroux and Josseron are with Aix-Marseille University, CNRS, ISM UMR 7287, Marseille, France. EspañaRomero and Cabeza de Vaca are with the Dept of Physical Education, School of Education, University of Cadiz, Puerto Real, Spain. Baláš and Kodejška are with the Faculty of Physical Education and Sport, Charles University, Prague, Czech Republic. Solar Altamirano is with the High Performance Center, National Inst of Sport, Ministry of Sport, Santiago, Chile. Mally and Beeretz are with Competence Center Sports Engineering, Biomechanics \& Ergonomics, University of Applied Sciences Technikum Wien, Vienna, Austria. Couceiro Canalejo is with the Physiology of Exercise Research Group, Universidad Politecnica de Madrid, Madrid, Spain. Arias Téllez is with the Dept of Nutrition, Faculty of Medicine, University of Chile, Santiago, Chile, and PROFITH, the "PROmoting FITness and Health through physical activity" Research Group, Dept of Physical and Sports Education, Faculty of Sports Science, University of Granada, Granada, Spain. Draper (nick.draper@ canterbury.ac.nz) is corresponding author. performance. In regard to the physiological aspects, 4 parameters have been regularly cited by coaches and researchers as key components of climbing that underpin performance. ${ }^{5}$ These physiological components are strength, power, flexibility, and endurance.$^{5-8}$ Given the importance of these factors for climbing, it is important to identify valid and reliable sport-specific tests that assess each of these parameters for use by researchers and coaches working with climbers.

The International Rock Climbing Research Association (IRCRA) was formed in 2011 to create a nexus for collaboration not only between countries and institutions but also between researchers, climbers, and coaches. In addition, through its biennial Congress and website forums, the IRCRA aims to bring greater consistency to research reporting. Examples of the IRCRA's work can be found in the publication of their position statement in regard to climbing grades. ${ }^{4}$ In this document, the IRCRA established a recommended format for study reporting to facilitate comparison between studies, clearer ability descriptors, and a numerical scale to bring greater consistency to statistical analyses. ${ }^{4}$

At the 2014 IRCRA Congress, held in Pontresina, Switzerland, the need for sport-specific assessment tools was highlighted by researchers and coaches. As a result of these discussions, a working group was established to develop a sport-specific battery of tests for coaches, climbers, and researchers. A key aspect of this development work was to ensure that the tests were valid, and reliable measures were taken so that they could be used as measurement tools for future intervention and cohort studies. The resultant multicenter trial established a collaboration between researchers and coaches from 7 countries across the globe with the purpose being to identify and assess the validity and reliability of a sport-specific test battery for rock climbing. 


\section{Methods}

This study involved 2 phases, with phase 1 being the development of the test battery and assessment for face and content validity. In phase 2 , the developed tests were assessed for construct validity and testretest reliability. While not a health study per se, the Consensusbased Standards for the Selection of Health Measurement Instruments was used to guide the development of the study and to evaluate the quality of each of the tests in the battery. ${ }^{9}$ After design and review using the Consensus-based Standards for the Selection of Health Measurement Instruments checklist, the study achieved good to excellent Consensus-based Standards for the Selection of Health Measurement Instruments rating prior to commencement. The study was approved by the University of Derby institutional research ethics committee (LSREC_1516_01). Informed consent from all participants was received before participation.

\section{Phase 1}

Following the IRCRA Congress in Pontresina, a working group comprising of academics, coaches/practitioners, and climbers ( $n=20$ ) was formed to develop the battery of tests using the Delphi method. ${ }^{10}$ Details of the working group can be found in the IRCRA Test Manual (see Supplementary Material [available online]). ${ }^{11}$ The working group endorsed the physiological parameters of strength, power, flexibility, and endurance, as previously identified in the research, but in addition included a fifth element of core stability, due to its importance with regard to quality movement in climbing. The battery of tests for the study underwent several stages in development, beginning with a desktop study. The desktop study identified the published sport-specific tests that had undergone validity and reliability assessment. This led to the inclusion of the flexibility assessment, ${ }^{8}$ maximal finger strength, ${ }^{12}$ and powerslap tests ${ }^{5}$ in the final test battery, as tests 1, 2, 3, and 5, respectively. Following this, in an iterative process, the working group further developed the climbing-specific foot raise ${ }^{8}$ to create tests 1 and 2 and then went on to develop, pilot test, revise, and agree on a further 6 tests for inclusion in the final test battery, ensuring that each of the agreed physiological components, including core stability, were assessed.

Each of the tests was examined for face and content validity prior to inclusion in the test battery through a process involving internationally recognized experts $(n=3)$ who met in person to revise and further develop each test to ensure the content validity of each test after face validity had been agreed by members of the working group $(n=6)$. The review process included the development of specific test apparatuses, in situ observations of climber performance on each of the tests, and a subjective assessment of the sport-specificity of each test. Full details of the tests including test apparatus specifications and protocols can be found in the test manual (see Supplementary Material [available online]). ${ }^{11}$ The final test battery, along with its associated physiological parameter(s), can also be found in IRCRA Test Manual (see Supplementary Material [available online]). ${ }^{11}$

\section{Phase 2}

\section{Participants}

As a multicenter trial, this study represents one of the largest completed with rock climbers, with 132 participants (mean [SD]) age 27.3 (7) years, body mass 65 (11) kg, height $170.5(9) \mathrm{cm}$, body mass index $22.4(2.5) \mathrm{kg} / \mathrm{m}^{2}$, body fat $17.7 \%(8 \%)$, who had 6.6 (6) years climbing experience and were, at the time of the study, training 2.5 (1) sessions per week. The participants consisted of 45 female and 87 male climbers, of whom 12 were tested in Austria, 21 in Chile, 15 in both the Czech Republic and France, 33 in Spain, and 36 in the United Kingdom. In Spain, the data were collected at 2 centers, one in Cadiz, the other in Madrid (Spain 1 and Spain 2, respectively). In 2011, the IRCRA published a classification system for climbers to provide a suggested ability-based nomenclature for reporting of climbing grades. ${ }^{4}$ This classification system being based on the validity of self-reported grades as had been previously demonstrated. ${ }^{13}$ The climbers, who completed a health history and informed consent prior to commencing their participation, self-reported as being of lower grade (20), intermediate (30), advanced (63), and elite (19) level. Specific characteristics of the group can be found in Table 1. The climber experience and health history questionnaires can be found on pages 22 and 33 of the Test Manual (see Supplementary Material [available online]), ${ }^{11}$ respectively.

\section{Procedure}

To assess the construct validity and reliability of each of the tests, a protocol for testing was established as shown in the IRCRA Test Manual (see Supplementary Material [available online]). ${ }^{11}$ To ensure each climber arrived at the laboratory in a similar physical condition, a minimum of 7 days was required between visits, and the participants were asked to rest completely in the 24 hours prior to each test. For each of the 3 laboratory visits, a 5-minute rest was allowed between tests. On each visit to the laboratory, the participants completed a standardized warm-up, which is described in detail in the test manual. The warm-up briefly consisted of 5 minutes of walking and jogging, 5 minutes of general mobilizing, and 5 minutes of specific exercises, such as pull-ups, leg raises, and reduced weight finger hangs, which mimicked the movement required in the tests. The warm-up was developed from methods used in previous research. ${ }^{14-16}$ Anthropometric measurements were made as described in the test manual, and it included height, mass, arm span, forearm volume, body density, and skinfold thicknesses. ${ }^{17-19}$ Version 1.6 of the test manual ${ }^{11}$ was followed at each of the test centers, along with e-mail and telephone clarifications, to ensure consistency of the method. In addition, videos were watched at each test center to ensure that the method for each test was the same across the study. Each test center built the test apparatuses to the specifications supplied in the test manual. For the leg raise tests ( $\mathrm{T} 1$ and $\mathrm{T} 2$ ), both left and right legs were tested for all participants. In T1, rotation at the shoulders was allowed, while for $\mathrm{T} 2$, no rotation at the shoulders was allowed, so the shoulders had to remain parallel to the test board during text execution. For the finger strength test (T3), both open and crimped holds were tested. For a description of different holds common to rock climbing, see Peters. ${ }^{20}$ For powerslap test (T5) and the bent-arm hang (T7), left and right arms were tested.

Construct validity for each of the tests was examined by ability level. (Higher grade climbers expected to have higher scores than lower grade climbers.) As can be seen in the IRCRA Test Manual (see Supplementary Material [available online]), for all tests with the exception of tests 3 and 5 (as described previously) and the 2 core stability tests (T9 and T10), were repeated to assess test-retest reliability between and across centers. At each of the centers, the researchers followed the protocol as described in the test manual to administer each of the tests. ${ }^{11}$ 
Table 1 Number of Participants in Each Ability Category and Mean (SD) Characteristics for the Climbers in the Study

\begin{tabular}{|c|c|c|c|c|c|}
\hline & All & Lower grade & Intermediate & Advanced & Elite \\
\hline \multicolumn{6}{|l|}{$\mathrm{N}$} \\
\hline Male & 87 & 13 & 19 & 44 & 11 \\
\hline Female & 45 & 7 & 11 & 19 & 8 \\
\hline \multicolumn{6}{|l|}{ Age, y } \\
\hline Male & $27.3(8)$ & $23.84(7)$ & $31.15(7)$ & $27.54(8)$ & $27.59(7)$ \\
\hline Female & $27.2(8)$ & $24.6(8)$ & $29.21(8)$ & $28.4(6)$ & 26.18 \\
\hline \multicolumn{6}{|c|}{ Body mass, $\mathrm{kg}$} \\
\hline Male & $69.8(14)$ & $80.68(15)$ & $68.81(8)$ & $67.58(8)$ & $71.45(5)$ \\
\hline Female & 57.3 (13) & $67.25(13)$ & $58.32(7)$ & $56.56(10)$ & $49.24(5)$ \\
\hline \multicolumn{6}{|l|}{ Height, $\mathrm{cm}$} \\
\hline Male & $174.6(27)$ & $177.51(6)$ & $174.93(8)$ & $172.99(7)$ & $176.75(2)$ \\
\hline Female & $162.3(25)$ & $164.05(6)$ & $166.16(8)$ & $161.92(9)$ & $158.76(6)$ \\
\hline \multicolumn{6}{|c|}{ Arm span, cm } \\
\hline Male & $180.3(33)$ & $180.99(4)$ & $179.1(9)$ & $179.61(9)$ & 185.49 (2) \\
\hline Female & $163.8(35)$ & $165.75(7)$ & $167.63(8)$ & $162.38(8)$ & $163.99(6)$ \\
\hline \multicolumn{6}{|c|}{ Body mass index, $\mathrm{kg} / \mathrm{m}^{2}$} \\
\hline Male & $22.8(4)$ & $25.59(4)$ & $22.45(2)$ & $22.56(2)$ & $22.88(2)$ \\
\hline Female & $21.7(4)$ & $24.91(4)$ & $21.12(2)$ & $21.45(2)$ & $19.5(1)$ \\
\hline \multicolumn{6}{|c|}{ Body fat, $\%$} \\
\hline Male & $13.7(6)$ & $18.38(5)$ & $13.15(6)$ & $13.63(5)$ & $11.86(2)$ \\
\hline Female & $24(7)$ & $28.46(7)$ & $24.79(5)$ & $24.35(7)$ & $18.81(4)$ \\
\hline \multicolumn{6}{|c|}{ Years climbing } \\
\hline Male & $7.4(6)$ & $3.52(6)$ & $6.95(6)$ & $8.22(6)$ & $13(7)$ \\
\hline Female & $5.2(4)$ & $2.65(2)$ & 3.77 (3) & $5.71(5)$ & $7.82(3)$ \\
\hline \multicolumn{6}{|c|}{ Sessions per week } \\
\hline Male & $2.7(1)$ & $1.05(0.7)$ & $2.79(1)$ & $2.92(1.3)$ & $3.56(1)$ \\
\hline Female & $2.5(1)$ & $0.81(0.4)$ & $1.75(0.6)$ & $2.71(1.1)$ & $4(1)$ \\
\hline
\end{tabular}

\section{Statistical Analysis}

Distributions, descriptive statistics, analyses of variance, correlations, and regressions were calculated using SPSS (version 25.0; IBM SPSS Statistics Inc, Chicago, IL), while Bland-Altman plots ${ }^{21,22}$ were calculated using Microsoft Excel (version 2016 MSO 16.0.4738.1000; Microsoft Redmond, Washington, WA). Data were assessed for violations of the assumptions of normality of distribution using the Shapiro-Wilk test with results showing Gaussian distribution. A 1-way analysis of variance with least-significantdifference post hoc comparisons as necessary was used to explore the effects of ability level on scores for each of the 10 tests. To ascertain the reliability of the tests, a series of Bland-Altman plots were completed, and coefficients of variation were calculated to examine the levels of agreement. Cronbach alpha and intraclass correlations were calculated to assess test-retest reliability. Data are reported as mean (SD), and $P \leq .05$ was set for accepting statistical significance.

\section{Results}

The means and SD for each of the tests are shown in Figure 1. As can be seen from this figure, the tests that appeared through visual inspection to differentiate climbers by ability category were the finger strength (T3-open and crimped, left and right), the finger hang (T4), the powerslap (T5), the bent-arm hang (T6), 1-arm bentarm hang (T7-left and right), and pull-ups test (T8).

Tests 1 and 2 (leg raise tests-flexibility) and tests 9 and 10 (plank and leg raise, respectively-core stability) did not appear to differentiate between climbers of differing abilities. The results of the analysis of variance tests (see Table 2) indicated that there were significant differences between groups for all tests with the exception of test 1 (right) and test 2 (left and right).

Visual inspection of the data in Table 2 suggests that in principle scores on tests improved with climbing ability; that is, high-grade climbers appeared to score higher on tests than their lower-ability counterparts. With regard to assessing construct validity, tests 4 and 6 performed well in differentiating between all grades of climbers. Test 5, when left and right powerslap were considered together, showed increased scores by ability. Test 8 showed good construct validity apart from differentiation between intermediate and advanced level climbers. Test 7 (single-arm bent-arm hang), which was similar to test 6 in showing significant differences by group, lacked differentiation for lower grade, intermediate, and advanced climbers. In these groups, there were several climbers who could not hold the 1-arm position at all, whereas they could with the 2-arm version (test 6). Tests $1,2,3,9$, and 10 performed poorly with respect to differentiation and could not be said to hold construct validity for climbing. 

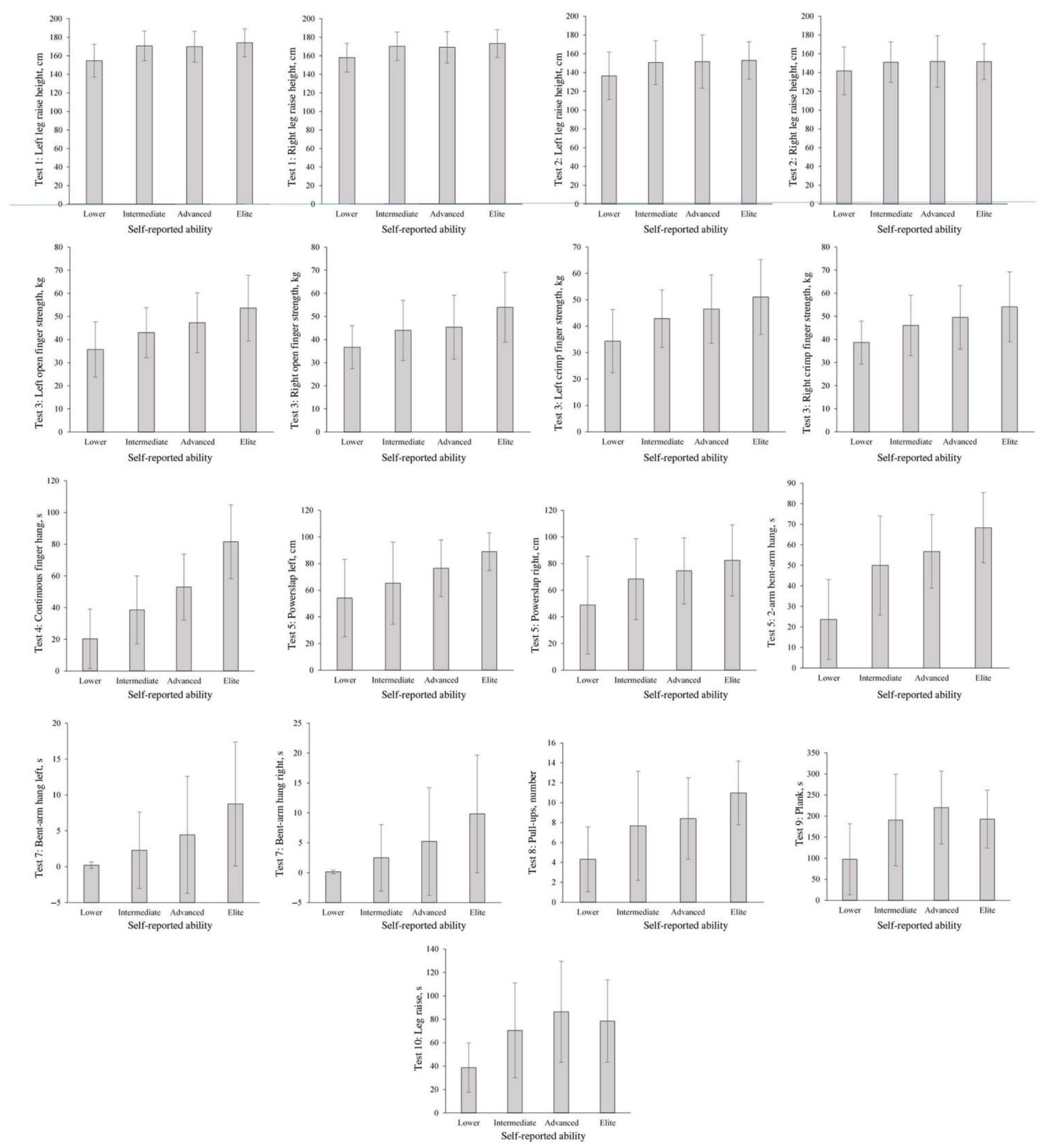

Figure 1 - Raw score means and SD for each of the tests, left and right hand shown as appropriate. Note. Results for test 1 are for leg raise with rotation and for test 2 are leg raise without rotation. 
Table 2 Results of ANOVA Tests for the International Rock Climbing Research Association Test Battery

\begin{tabular}{|c|c|c|c|c|c|c|c|c|c|}
\hline \multirow[b]{2}{*}{ Test } & \multicolumn{3}{|c|}{ ANOVA } & \multirow[b]{2}{*}{$1-2$} & \multirow[b]{2}{*}{$1-3$} & \multirow[b]{2}{*}{$1-4$} & \multirow[b]{2}{*}{$2-3$} & \multirow[b]{2}{*}{$2-4$} & \multirow[b]{2}{*}{$3-4$} \\
\hline & $F$ & $P$ & $\eta_{\mathrm{p}}^{2}$ & & & & & & \\
\hline \multicolumn{10}{|c|}{ Test 1: Left leg raise } \\
\hline Combined & 4.218 & .007 & .101 & $*$ & $*$ & $*$ & & & \\
\hline Male & 7.167 & $<.0005$ & .228 & $*$ & $*$ & $*$ & & & $*$ \\
\hline Female & 0.299 & .826 & .024 & & & & & & \\
\hline \multicolumn{10}{|c|}{ Test 1: Right leg raise } \\
\hline Combined & 2.588 & .057 & .064 & & & & & & \\
\hline Male & 5.167 & .003 & .175 & $*$ & $*$ & $*$ & & & $*$ \\
\hline Female & 0.251 & .860 & .02 & & & & & & \\
\hline \multicolumn{10}{|c|}{ Test 2: Left leg raise } \\
\hline Combined & 0.994 & .399 & .026 & & & & & & \\
\hline Male & 3.032 & .035 & .111 & * & $*$ & $*$ & & & \\
\hline Female & 0.611 & 612 & .048 & & & & & & \\
\hline \multicolumn{10}{|c|}{ Test 2: Right leg raise } \\
\hline Combined & 0.642 & .589 & .017 & & & & & & \\
\hline Male & 1.711 & .172 & .066 & & & & & & \\
\hline Female & 0.425 & .736 & .034 & & & & & & \\
\hline \multicolumn{10}{|c|}{ Test 3: Left open finger strength } \\
\hline Combined & 4.42 & .006 & .127 & & $*$ & $*$ & & $*$ & \\
\hline Male & 8.788 & $<.0005$ & .305 & & $*$ & $*$ & $*$ & $*$ & $*$ \\
\hline Female & 4.021 & .017 & .309 & $*$ & * & $*$ & & & \\
\hline \multicolumn{10}{|c|}{ Test 3: Right open finger strength } \\
\hline Combined & 3.707 & .014 & .106 & & $*$ & $*$ & & $*$ & \\
\hline Male & 5.901 & .001 & .219 & & $*$ & $*$ & & $*$ & $*$ \\
\hline Female & 2.551 & .077 & .221 & & * & $*$ & & & \\
\hline \multicolumn{10}{|c|}{ Test 3: Left crimp finger strength } \\
\hline Combined & 3.997 & .010 & .113 & & $*$ & $*$ & & & \\
\hline Male & 4.811 & .004 & .186 & & $*$ & $*$ & & $*$ & \\
\hline Female & 3.528 & .028 & .282 & & $*$ & $*$ & & $*$ & \\
\hline \multicolumn{10}{|c|}{ Test 3: Right crimp finge strength } \\
\hline Combined & 3.145 & .029 & .094 & & $*$ & $*$ & & & \\
\hline Male & 4.413 & .007 & .181 & & $*$ & $*$ & & $*$ & $*$ \\
\hline Female & 6.132 & .003 & .405 & & & & & & \\
\hline \multicolumn{10}{|c|}{ Test 4: Continuous finger hang } \\
\hline Combined & 24.235 & $<.0005$ & .394 & $*$ & $*$ & $*$ & $*$ & $*$ & $*$ \\
\hline Male & 12.430 & $<.0005$ & .341 & $*$ & $*$ & $*$ & & * & $*$ \\
\hline Female & 16.618 & $<.0005$ & .581 & & $*$ & $*$ & $*$ & $*$ & $*$ \\
\hline \multicolumn{10}{|c|}{ Test 5: Left powerslap } \\
\hline Combined & 6.758 & $<.0005$ & .151 & & $*$ & $*$ & $*$ & $*$ & \\
\hline Male & 9.220 & $<.0005$ & .275 & $*$ & $*$ & $*$ & & $*$ & $*$ \\
\hline Female & 12.746 & $<.0005$ & .508 & & $*$ & $*$ & $*$ & $*$ & $*$ \\
\hline \multicolumn{10}{|c|}{ Test 5: Right powerslap } \\
\hline Combined & 4.347 & .006 & .103 & $*$ & $*$ & $*$ & & & \\
\hline Male & 5.171 & .003 & .175 & * & $*$ & $*$ & & & \\
\hline Female & 7.891 & $<.0005$ & .390 & $*$ & $*$ & $*$ & $*$ & $*$ & \\
\hline Test 6: 2-arm & & & & & & & & & \\
\hline Combined & 15.259 & $<.0005$ & .287 & $*$ & $*$ & $*$ & & $*$ & $*$ \\
\hline Male & 13.122 & $<.0005$ & .350 & * & * & $*$ & & $*$ & $*$ \\
\hline Female & 8.432 & $<.0005$ & .406 & * & * & $*$ & & * & \\
\hline
\end{tabular}


Table 2 (continued)

\begin{tabular}{|c|c|c|c|c|c|c|c|c|c|}
\hline \multirow[b]{2}{*}{ Test } & \multicolumn{3}{|c|}{ ANOVA } & \multirow[b]{2}{*}{$1-2$} & \multirow[b]{2}{*}{$1-3$} & \multirow[b]{2}{*}{$1-4$} & \multirow[b]{2}{*}{$2-3$} & \multirow[b]{2}{*}{$2-4$} & \multirow[b]{2}{*}{$3-4$} \\
\hline & $F$ & $P$ & $\eta_{\mathrm{p}}^{2}$ & & & & & & \\
\hline \multicolumn{10}{|c|}{ Test 7: Left bent-arm hang } \\
\hline Combined & 4.478 & .005 & .105 & & $*$ & $*$ & & $*$ & $*$ \\
\hline Male & 4.756 & .004 & .163 & & * & $*$ & & $*$ & $*$ \\
\hline Female & 3.764 & .019 & .234 & & & $*$ & & $*$ & $*$ \\
\hline \multicolumn{10}{|c|}{ Test 7: Right bent-arm hang } \\
\hline Combined & 4.856 & .003 & .113 & & $*$ & $*$ & & $*$ & $*$ \\
\hline Male & 5.689 & .001 & .189 & & $*$ & $*$ & & $*$ & $*$ \\
\hline Female & 1.863 & .153 & .131 & & & & & & \\
\hline \multicolumn{10}{|c|}{ Test 8: Pull-ups } \\
\hline Combined & 5.464 & .002 & .113 & $*$ & $*$ & $*$ & & $*$ & $*$ \\
\hline Male & 8.088 & $<.0005$ & .260 & $*$ & $*$ & * & & $*$ & $*$ \\
\hline Female & 8.397 & $<.0005$ & .426 & & $*$ & $*$ & & $*$ & $*$ \\
\hline \multicolumn{10}{|l|}{ Test 9: Plank } \\
\hline Combined & 7.385 & $<.0005$ & .163 & $*$ & $*$ & * & & & \\
\hline Male & 3.697 & .015 & .132 & $*$ & $*$ & & & & \\
\hline Female & 6.311 & .001 & .338 & $*$ & $*$ & $*$ & & & \\
\hline \multicolumn{10}{|c|}{ Test 10: Leg raise } \\
\hline Combined & 5.723 & .001 & .113 & $*$ & $*$ & * & & & \\
\hline Male & 2.329 & .082 & .088 & & & & & & \\
\hline Female & 4.890 & .006 & .290 & & $*$ & $*$ & $*$ & & \\
\hline
\end{tabular}

Abbreviation: ANOVA, analysis of variance.

*Significant post hoc difference between these groups $(P<.05)$, also indicated by bold $P$ values.

About reliability, only tests 4,6 , and 8 were assessed for testretest reliability, as these were the tests which displayed strong construct validity. Test 5 , the powerslap test, performed well in regard to construct validity and had already been assessed for testretest reliability in a previous study, so this was not replicated in our test protocol (5). The results of Cronbach alpha and intraclass correlations tests can be seen in Table 3. As can be seen from Table 3, all 3 tests displayed strong test-retest reliability as a whole (across countries) and also within each country. The only exception being French data for the finger hang and 2-arm bent-arm hang which had a moderate result $(0.771$ and $0.624 ; 0.657$ and 0.480 , respectively).

The Bland-Altman plots for each of the 3 tests can be seen in Figure 2. As can be seen in this figure, there were good levels of agreement between tests. Table 4 provides the coefficient of variation for tests $4,5,6$, and 8 . Taken across all grades, the tests demonstrated very good to acceptable levels of variation. On tests 4 and 8 for lower grade females, the variation $>30 \%$ is not acceptable.

Tests $4,5,6$, and 8 demonstrated strong construct validity, showed good levels of agreement, and displayed strong test-retest reliability. Table 5 provides details of regression modeling for tests 4 , 5,6 , and 8 . As can be seen from this modeling, the variance explained across all models was higher for females $\left(R^{2}=.52-.58\right)$ than for males $\left(R^{2}=.31-.36\right)$. For both males and females, the variance explained increased only marginally when moving from model 2 to 3 and including the 2-arm bent-arm hang (T6) and pull-ups (8).

\section{Discussion}

Research across many sports has highlighted the benefits of valid and reliable, sport-specific tests for monitoring performance in athletes. ${ }^{23-25}$ Although a generally more recent area of research focus, the need for sport-specific measurement tools for rock climbing has been recognized by coaches and researchers alike, and there are an increasing number of studies examining novel tests for the sport. $1,5,8,12,26,27$ These studies have, however, been limited in regard to the total number and ability levels of the participants. The mission of the IRCRA is to foster collaboration not only between researchers, coaches, and climbers but also between countries to increase our knowledge and understanding of the sport. This is increasingly important from a performance perspective since the inclusion of rock climbing in the Olympic schedule for the Tokyo 2021 Olympic Games. The collaboration brought about through the IRCRA enabled the establishment of the largest rock climbing study to date with data collected from centers in 7 countries where climbing is a popular performance and recreational activity. The aim of the resultant study was to examine the validity, reliability, and performance assessment potential of 10 sport-specific performance measures for rock climbing.

Researchers identified flexibility, power, strength, and endurance as the key performance parameters for rock climbing, with the recognition that core stability plays an additional key role in successful performance. ${ }^{5-8,12,26}$ Through the Delphi method, an expert panel identified, developed, and refined the protocol for 10 sport-specific rock climbing tests to be included in the study. The key finding of the study was that tests $4,5,6$, and 8 , namely the finger hang, powerslap, 2-arm bent-arm hang, and the pull-ups tests respectively, demonstrated high levels of validity and reliability as sport-specific measures. As shown in Table 1, these tests were designed to assess climbing-specific endurance and power. The remaining tests, tests $1,2,3,7,9$, and 10, which assessed climbingspecific flexibility, strength, endurance, and core stability did not 
Table 3 Cronbach Alpha, ICC, and Lower and Higher Limits for Tests 4 (Finger Hang), 6 (2-Arm Bent-Arm Hang), and 8 (Pull-Ups)

\begin{tabular}{|c|c|c|c|c|}
\hline & C alpha & ICC & $95 \%$ lower & $95 \%$ higher \\
\hline \multicolumn{5}{|l|}{ Finger hang } \\
\hline \multicolumn{5}{|l|}{ All } \\
\hline Combined & .937 & .881 & .835 & .915 \\
\hline Male & .939 & .887 & .831 & .925 \\
\hline Female & .926 & .865 & .758 & .927 \\
\hline \multicolumn{5}{|l|}{ French } \\
\hline Combined & .771 & .624 & .182 & .860 \\
\hline Male & .834 & .724 & .292 & .912 \\
\hline Female & - & - & - & - \\
\hline \multicolumn{5}{|l|}{ Czech } \\
\hline Combined & .982 & .962 & .890 & .987 \\
\hline Male & .975 & .952 & .816 & .989 \\
\hline Female & .979 & .955 & .756 & .993 \\
\hline \multicolumn{5}{|l|}{ Austria } \\
\hline Combined & .944 & .895 & 672 & .970 \\
\hline Male & .931 & .875 & .329 & .986 \\
\hline Female & .819 & .722 & -.106 & .952 \\
\hline \multicolumn{5}{|l|}{ Britain } \\
\hline Combined & .932 & .869 & .738 & .937 \\
\hline Male & .916 & .839 & .650 & .931 \\
\hline Female & .836 & .747 & .036 & .952 \\
\hline \multicolumn{5}{|l|}{ Chile } \\
\hline Combined & .946 & .887 & .737 & .953 \\
\hline Male & .924 & .825 & .473 & .945 \\
\hline Female & .917 & .861 & .451 & .971 \\
\hline \multicolumn{5}{|l|}{ Spain S1 } \\
\hline Combined & .909 & .844 & .578 & .947 \\
\hline Male & .888 & .81 & .437 & .945 \\
\hline Female & - & - & - & - \\
\hline \multicolumn{5}{|l|}{ Spain S2 } \\
\hline Combined & .945 & .887 & .734 & .954 \\
\hline Male & .959 & .919 & .764 & .974 \\
\hline Female & .916 & .84 & .389 & .970 \\
\hline \multicolumn{5}{|l|}{ 2-arm bent hang } \\
\hline \multicolumn{5}{|l|}{ All } \\
\hline Combined & .944 & .894 & .852 & .925 \\
\hline Male & .926 & .864 & .797 & .910 \\
\hline Female & .954 & .913 & .841 & .954 \\
\hline \multicolumn{5}{|l|}{ French } \\
\hline Combined & .657 & .480 & -.016 & .794 \\
\hline Male & .112 & .062 & -.577 & .626 \\
\hline Female & - & - & - & - \\
\hline \multicolumn{5}{|l|}{ Czech } \\
\hline Combined & .962 & .928 & .804 & .957 \\
\hline Male & .893 & .824 & .385 & .958 \\
\hline Female & .961 & .913 & .558 & .987 \\
\hline \multicolumn{5}{|l|}{ Austria } \\
\hline Combined & .974 & .929 & .674 & .982 \\
\hline Male & .937 & .900 & .315 & .989 \\
\hline
\end{tabular}

Table 3 (continued)

\begin{tabular}{|c|c|c|c|c|}
\hline & C alpha & ICC & $95 \%$ lower & $95 \%$ higher \\
\hline Female & .988 & .892 & -.032 & .987 \\
\hline \multicolumn{5}{|l|}{ British } \\
\hline Combined & .927 & .842 & .649 & .928 \\
\hline Male & .872 & .740 & .438 & .888 \\
\hline Female & .941 & .875 & .430 & .981 \\
\hline \multicolumn{5}{|l|}{ Chile } \\
\hline Combined & .919 & .808 & .493 & .925 \\
\hline Male & .774 & .567 & .074 & .842 \\
\hline Female & .979 & .938 & .626 & .988 \\
\hline \multicolumn{5}{|l|}{ Spain S1 } \\
\hline Combined & .978 & .956 & .872 & .985 \\
\hline Male & .976 & .955 & .848 & .987 \\
\hline Female & - & - & - & - \\
\hline \multicolumn{5}{|l|}{ Spain S2 } \\
\hline Combined & .905 & .830 & .623 & .929 \\
\hline Male & .964 & .931 & .797 & .978 \\
\hline Female & .844 & .757 & .061 & .954 \\
\hline \multicolumn{5}{|l|}{ Pull-ups } \\
\hline \multicolumn{5}{|l|}{ All } \\
\hline Combined & .99 & .972 & .922 & .986 \\
\hline Male & .984 & .953 & .855 & .979 \\
\hline Female & .987 & .969 & .922 & .985 \\
\hline \multicolumn{5}{|l|}{ French } \\
\hline Combined & .986 & .967 & .896 & .989 \\
\hline Male & .978 & .947 & .806 & .985 \\
\hline Female & - & - & - & - \\
\hline \multicolumn{5}{|l|}{ Czech } \\
\hline Combined & .991 & .974 & .856 & .993 \\
\hline Male & .901 & .728 & .078 & .935 \\
\hline Female & .958 & .904 & .510 & .968 \\
\hline \multicolumn{5}{|l|}{ Austria } \\
\hline Combined & .989 & .971 & .884 & .992 \\
\hline Male & .997 & .995 & .969 & .999 \\
\hline Female & .860 & .663 & -.540 & .943 \\
\hline \multicolumn{5}{|l|}{ British } \\
\hline Combined & .995 & .986 & .954 & .995 \\
\hline Male & .992 & .977 & .893 & .992 \\
\hline Female & .986 & .972 & .878 & .994 \\
\hline \multicolumn{5}{|l|}{ Chile } \\
\hline Combined & .989 & .971 & .904 & .989 \\
\hline Male & .984 & .960 & .837 & .988 \\
\hline Female & .961 & .916 & .656 & .982 \\
\hline \multicolumn{5}{|l|}{ Spain S1 } \\
\hline Combined & .969 & .923 & .731 & .976 \\
\hline Male & .956 & .890 & .586 & .970 \\
\hline Female & - & - & - & - \\
\hline \multicolumn{5}{|l|}{ Spain S2 } \\
\hline Combined & .960 & .886 & .567 & .961 \\
\hline Male & .854 & .635 & .053 & .881 \\
\hline Female & .986 & .965 & .823 & .993 \\
\hline
\end{tabular}

Abbreviations: ICC, intraclass correlations. Note: When participant numbers were $\leq 3$, the statistics were not calculated. 

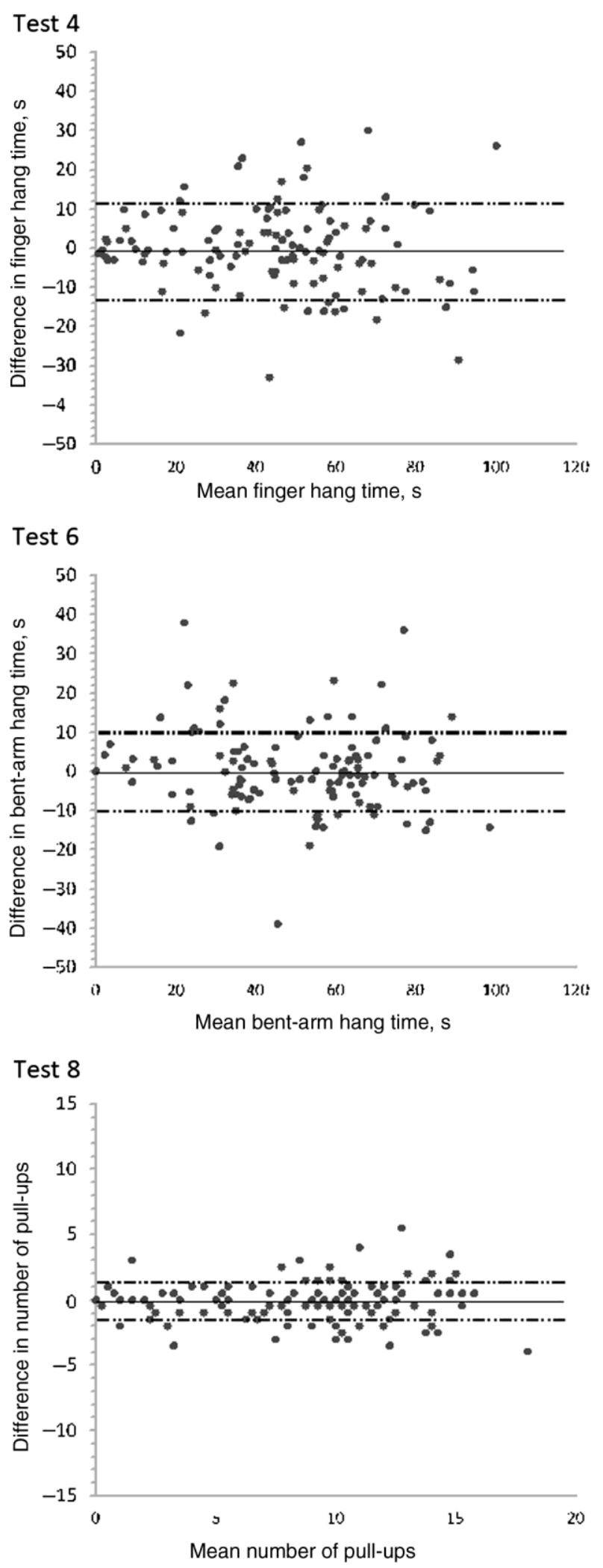

Figure 2 - Bland-Altman plots for finger hang (test 4), 2-arm bent-arm hang (test 6), and pull-ups (test 8). 
Table 4 Coefficients of Variation for Each of the Selected Tests

\begin{tabular}{|c|c|c|c|c|c|}
\hline Test & All, \% & Lower grade, \% & Intermediate, $\%$ & Advanced, \% & Elite, \% \\
\hline \multicolumn{6}{|c|}{ Test 4: Finger hang } \\
\hline All & 18 & 32 & 22 & 12 & 13 \\
\hline Male & 16 & 25 & 18 & 12 & 10 \\
\hline Female & 24 & 53 & 29 & 11 & 16 \\
\hline \multicolumn{6}{|c|}{ Test 5: Powerslap } \\
\hline All & 7 & 14 & 11 & 4 & 3 \\
\hline Male & 4 & 6 & 5 & 3 & 3 \\
\hline Female & 13 & 34 & 23 & 6 & 2 \\
\hline \multicolumn{6}{|c|}{ Test 6: 2-arm bent hang } \\
\hline All & 15 & 24 & 17 & 11 & 18 \\
\hline Male & 13 & 13 & 18 & 11 & 9 \\
\hline Female & 19 & 56 & 15 & 11 & 27 \\
\hline \multicolumn{6}{|c|}{ Test 8: Pull-ups } \\
\hline All & 14 & 19 & 18 & 13 & 5 \\
\hline Male & 10 & 10 & 11 & 9 & 6 \\
\hline Female & 24 & 47 & 31 & 20 & 5 \\
\hline
\end{tabular}

perform as well in regard to validity for rock climbing and in their current forms could not be considered as sport-specific measures across all ability levels.

Flexibility, the component designed to be assessed in tests 1 and 2 , had been studied in a wider series of flexibility tests by Draper et al. ${ }^{8}$ In this 2-phase pilot study, with 46 and then 21 participants, 6 flexibility measures were assessed for validity and reliability. This study found significant differences between elite climbers and lower grade (novice) and intermediate climbers but not advanced climbers. ${ }^{8}$ Our research could not support this finding with only the left foot raise in test 1 identifying a significant but limited difference between the groups (Table 3). Taken together, our study and the previous one perhaps suggest that flexibility is important for climbing, but there may be a threshold above which this fitness component becomes a lesser determinant of performance. Examining the data from the 2 studies, it is a threshold that perhaps differentiates advanced and elite climbers from intermediate and lower grade climbers. Once this threshold is reached, flexibility is not a critical component that differentiates performance at advanced and elite levels. Further research in this area might examine the potential of a new combination of tests, such as the lateral foot raise test and footloading flexibility test, ${ }^{8}$ to examine whether there is a further differential improvement in flexibility above the intermediate level. In future work with athletes at lower grade and intermediate levels, it may be beneficial to assess flexibility to examine if it is a rate limiter for performance improvement. However, for higher grade climbers perhaps only after returning to climbing after injury would assessment of flexibility merit inclusion in a battery of tests for climbers of advanced and elite level.

Strength, particularly grip strength, has been highlighted by coaches and researchers as a key component of fitness for climbers. ${ }^{7,12,15}$ Our results lend support to the importance of strength for rock climbers with significant differences in strength across groups for finger open and crimp with both right and left hand. The results, however, indicate significant differences between advanced and elite climbers in comparison to lower grade climbers and elite climbers with intermediate climbers, but the tests do not differ across all categories of climbers. This data suggest that there is a threshold that distinguishes elite and advanced climbers from lower ability climbers, but not across all grades of climbers.

Test 7, the 1-arm bent-arm hang (right and left arm), also assessed endurance in a similar manner to test 6 (the 2-arm version); however, results showed that this test had limitations regarding lower grade, intermediate and advanced climbers, many of whom scored zero for this test. While the group means, as shown in Figure 2, reveal increases in the mean score by ability group, the results also revealed that all the lower grade climbers, and many of the intermediate and even advanced level climbers, scored zero for the test, meaning that they were not able to hold this position at all. For the 2 -arm version, test 6 , all climbers were able to score on the test, and it did provide good differentiation between ability groups. As a result of this finding, test 7 could only be recommended as a performance measure for elite climbers; however, test 6 provides a valid and reliable measure for all climbers.

Core stability was identified by our expert panel as an important component for climbing performance. As a consequence, tests 9 and 10 were designed, in an exploratory manner, as potential measures of core stability that might distinguish climbers of differing abilities. Results of testing revealed a similar pattern for both tests, with performance improving up to the advanced level, but with mean scores for elite climbers not as high as those for advanced climbers. Furthermore, intermediate, advanced, and elite climbers performed significantly $(P<.05)$ better on both tests than lower grade climbers. Both tests were conducted to volitional failure, and it is possible that while advanced climbers displayed greater core stability than lower grade and intermediate climbers, the elite climbers reached their volitional limit earlier due to psychological aspects, which provides a limitation to both tests. This finding is in keeping with work by Leetun et al, ${ }^{28}$ along with Weir et al, ${ }^{29}$ who found that while core stability is likely an important performance parameter that is difficult to measure reliably and may be highly sportspecific. Further research on sport-specific measures would be required for climbing, prior to their inclusion in a battery of tests 
Table 5 Results of Regression Modeling Using Tests 4, 5, 6, and 8 (Finger Hang, Powerslap, 2-Arm Bent-Arm Hang, and Pull-Ups, Respectively), With the Dependent Variable of Climbing Ability

\begin{tabular}{|c|c|c|c|c|}
\hline & \multicolumn{4}{|c|}{ Dependent variable: Climbing ability } \\
\hline & $B$ & SE $B$ & $\beta$ & $P$ \\
\hline \multicolumn{5}{|l|}{ Combined } \\
\hline \multicolumn{5}{|c|}{ Model 1: $R^{2}=.39 ; \Delta R^{2}=.38 ; P<.001^{*}$} \\
\hline Finger hang & 0.109 & 0.013 & 0.621 & $.001 *$ \\
\hline \multicolumn{5}{|c|}{ Model 2: $R^{2}=.46 ; \Delta R^{2}=.45 ; P<.001 *$} \\
\hline Finger hang & 0.082 & 0.015 & 0.465 & $.001 *$ \\
\hline Powerslap & 0.060 & 0.016 & 0.314 & $.001 *$ \\
\hline \multicolumn{5}{|c|}{ Model 3: $R^{2}=.47 ; \Delta R^{2}=.45 ; P<.001 *$} \\
\hline Finger hang & 0.077 & 0.017 & 0.437 & $.001 *$ \\
\hline Powerslap & 0.036 & 0.023 & 0.191 & .123 \\
\hline Bent arm & -0.007 & 0.024 & -0.032 & .769 \\
\hline Pull-ups & 0.186 & 0.132 & 0.193 & .162 \\
\hline \multicolumn{5}{|l|}{ Female } \\
\hline \multicolumn{5}{|c|}{ Model $1: R^{2}=.52 ; \Delta R^{2}=.51 ; P<.001^{*}$} \\
\hline Finger hang & 0.095 & 0.015 & 0.723 & $.001 *$ \\
\hline \multicolumn{5}{|c|}{ Model $2: R^{2}=.56 ; \Delta R^{2}=.53 ; P<.001 *$} \\
\hline Finger hang & 0.077 & 0.019 & 0.582 & $.001^{*}$ \\
\hline Powerslap & 0.044 & 0.028 & 0.230 & .122 \\
\hline \multicolumn{5}{|c|}{ Model 3: $R^{2}=.58 ; \Delta R^{2}=.53 ; P<.001^{*}$} \\
\hline Finger hang & 0.069 & 0.022 & 0.526 & $.004^{*}$ \\
\hline Powerslap & 0.031 & 0.032 & 0.158 & .343 \\
\hline Bent arm & -0.034 & 0.036 & -0.176 & .354 \\
\hline Pull-ups & 0.313 & 0.221 & 0.303 & .167 \\
\hline \multicolumn{5}{|l|}{ Male } \\
\hline \multicolumn{5}{|c|}{ Model $1: R^{2}=.31 ; \Delta R^{2}=.30 ; P<.001 *$} \\
\hline Finger hang & 0.110 & 0.020 & 0.556 & $.001 *$ \\
\hline \multicolumn{5}{|c|}{ Model $2: R^{2}=.35 ; \Delta R^{2}=.33 ; P<.001 *$} \\
\hline Finger hang & 0.088 & 0.022 & 0.445 & $.001 *$ \\
\hline Powerslap & 0.071 & 0.034 & 0.230 & $.001 *$ \\
\hline \multicolumn{5}{|c|}{ Model 3: $R^{2}=.36 ; \Delta R^{2}=.32 ; P<.001 *$} \\
\hline Finger hang & 0.081 & 0.026 & 0.410 & $.002 *$ \\
\hline Powerslap & 0.050 & 0.042 & 0.165 & .229 \\
\hline Bent arm & 0.002 & 0.031 & 0.008 & .953 \\
\hline Pull-ups & 0.147 & 0.177 & 0.120 & .410 \\
\hline
\end{tabular}

for elite climbers. These tests might prove beneficial with lower grade and intermediate climbers in the context of studies designed to improve climber performance.

\section{Practical Application}

Valid and reliable sport-specific measures of physiological functioning are vital in the preparation of athletes for competition. The results of our research for the new Olympic sport of rock climbing verify the suitability of the finger hang and powerslap tests as valid and reliable sport-specific performance measures for use by researchers, coaches, and climbers. Coaches could use these tests to assess physiological adaptation brought about through prescribed training programs implemented for climbers from lower grade to the elite levels.

\section{Conclusion}

The results of our study suggest that if only one test was possible in a research context, the finger hang, test 4 , is a reliable measure that can distinguish across all ability levels. If a more complete picture of climbing performance is required, then researchers might consider including tests 4 and 5 (finger hang and powerslap) with scores on these 2 tests able to account for $35 \%$ to $56 \%$ of the variance between climbers for males and females, respectively. Given the physiological overlap between tests 4,6 , and 8 and the lack of further explained variance through regression modeling when tests 6 and 8 (2-arm bent-arm hang and pull-ups) are added to the test battery, it can only be recommended to include the finger hang and powerslap in a test battery when using climbers of different ability levels. The results of 
our study indicate that future research is required to identify tests of flexibility, strength, and core stability that are specific to climbing and can differentiate between ability groups. Future studies should also examine the effect of age on scoring in these tests, in work similar to Malina et $\mathrm{al}^{30}$ for soccer.

\section{References}

1. Abreu EAC, Araújo SRS, Cançado GHDCP, Andrade AGP, Chagas MH, Menzel HK. TEST-retest reliability of kinetic variables measured on campus board in sport climbers. Sports Biomech. 2018; 18(6):649-662. doi:10.1080/14763141.2018.1456558

2. Nichols J, Wing D, Bellicini Z, et al. Climbing-specific fitness profiles and determinants of performance in youth rock climbers. J Sports Sci. 2018;6:257-267. doi:10.17265/2332-7839/2018.05.001

3. Ginszt M, Michalak-Wojnowska M, Gawda P, et al. ACTN3 Genotype in Professional Sport Climbers. J Strength Cond Res. 2018; 32(5):1311. doi:10.1519/JSC.0000000000002457

4. Draper N, Giles D, Schöffl V, et al. Comparative grading scales, statistical analyses, climber descriptors and ability grouping: International Rock Climbing Research Association position statement. Sports Tech. 2015;8(3-4):88-94. doi:10.1080/19346182.2015. 1107081

5. Draper N, Dickson T, Blackwell G, et al. Sport-specific power assessment for rock climbing. J Sports Med Phys Fitness. 2011;51(3): 417-425. PubMed ID: 21904280

6. Draper N, Hodgson C. Adventure Sport Physiology. Chichester, UK: John Wiley \& Sons; 2008.

7. MacLeod D, Sutherland D, Buntin L, et al. Physiological determinants of climbing-specific finger endurance and sport rock climbing performance. J Sports Sci. 2007;25(12):1433-1443. PubMed ID: 17786696 doi:10.1080/02640410600944550

8. Draper N, Brent S, Hodgson C, Blackwell G. Flexibility assessment and the role of flexibility as a determinant of performance in rock climbing. Int J Perform Anal Sport. 2009;9(1):67-89. doi:10.1080/ 24748668.2009.11868465

9. Mokkink LB, Terwee CB, Patrick DL, et al. The COSMIN checklist for assessing the methodological quality of studies on measurement properties of health status measurement instruments: an international Delphi study. Qual Life Res. 2010;19(4):539-549. PubMed ID: 20169472 doi:10.1007/s11136-010-9606-8

10. Okoli C, Pawlowski SD. The Delphi method as a research tool: an example, design considerations and applications. Inf Manag. 2004; 42(1):15-29. doi:10.1016/j.im.2003.11.002

11. Giles D, Draper, N. The IRCRA performance-related test battery for climbers 2015. Version 1.6. 2015. https://www.ircra.rocks/mctdocuments. Updated November 18, 2015.

12. Baláš J, MrskoČ J, PanáČková M, Draper N. Sport-specific finger flexor strength assessment using electronic scales in sport climbers. Sports Tech. 2014;7(3-4):151-158. doi:10.1080/19346182.2015.1012082

13. Draper N, Canalejo JC, Fryer S, et al. Reporting climbing grades and grouping categories for rock climbing. Isokinet Exerc Sci. 2011;19(4): 273-280. doi:10.3233/IES20110424

14. Binney D, McClure S. Aerobic and anaerobic power: power endurance. Climb. 2006:64, 66.
15. Gresham N. Training and technique for climbers of all levels. Climber. 2007:78-80.

16. Tenke Z, Higgins A. Warm-Up and Preparation for Athletes of All Sports. Toronto, Canada: Sports Book Publishers; 1994:1-84.

17. Durnin JV, Womersley J. Body fat assessed from total body density and its estimation from skinfold thickness: measurements on 481 men and women aged from 16 to 72 years. Br J Nutr. 1974;32(1):77-97. doi:10.1079/BJN19740060

18. Heyward VH, Gibson AL. Advanced Fitness Assessment and Exercise Prescription. 7th ed. Champaign, IL: Human Kinetics; 2014:1-552.

19. Siri WE. Techniques for measuring body composition. In: Brolek J, Henschel A, eds. Techniques for Measuring Body Composition. Washington, DC: National Academy of Sciences National Research Council; 1961:223-244.

20. Peters L. Rock Climbing Essential Skills and Techniques. Capel Curig, UK: Mountain Leader Training UK; 2004:1-272.

21. Altman DG, Bland JM. Measurement in medicine: the analysis of method comparison studies. Statistician. 1983;32(3):307-317. doi:10.2307/2987937

22. Bland JM, Altman DG. Statistical methods for assessing agreement between two methods of clinical measurement. Lancet. 1986; 327(8476):307-310. doi:10.1016/S0140-6736(86)90837-8

23. Uljevic O, Esco MR, Sekulic D. Reliability, validity, and applicability of isolated and combined sport-specific tests of conditioning capacities in top-level junior water polo athletes. J Strength Cond Res. 2014;28(6):1595-1605. doi:10.1519/JSC.0000000000000308

24. Rodríguez-Rosell D, Mora-Custodio R, Franco-Márquez F, YáñezGarcía JM, González-Badillo JJ. Traditional vs. sport-specific vertical jump tests: reliability, validity, and relationship with the legs strength and sprint performance in adult and teen soccer and basketball players. J Str Cond Res. 2017;31(1):196-206. doi:10.1519/JSC. 0000000000001476

25. Spasic M, Krolo A, Zenic N, Delextrat A, Sekulic D. Reactive agility performance in handball; development and evaluation of a sportspecific measurement protocol. J Sports Sci Med. 2015;14(3):501. PubMed ID: 26336335

26. Michailov ML, Morrison A, Ketenliev MM, Pentcheva BP. A sportspecific upper-body ergometer test for evaluating submaximal and maximal parameters in elite rock climbers. Int J Sports Physiol Perf. 2015;10(3):374-380. doi:10.1123/ijspp.2014-0160

27. Brent S, Draper N, Hodgson C, Blackwell G. Development of a performance assessment tool for rock climbers. Eur J Sport Sci. 2009;9(3):159-167. doi:10.1080/17461390902741132

28. Leetun DT, Ireland ML, Willson JD, Ballantyne BT, Davis IM. Core stability measures as risk factors for lower extremity injury in athletes. Med Sci Sports Exec. 2004;36(6):926-934. doi:10.1249/01.MSS. 0000128145.75199.C3

29. Weir A, Darby J, Inklaar H, Koes B, Bakker E, Tol JL. Core stability: inter-and intraobserver reliability of 6 clinical tests. Clin J Sport Med. 2010;20(1):34-38. PubMed ID: 20051732 doi:10.1097/JSM. 0b013e3181cae924

30. Malina RM, Cumming SP, Kontos AP, Eisenmann JC, Ribeiro B, Aroso J. Maturity-associated variation in sport-specific skills of youth soccer players aged 13-15 years. J Sports Sci. 2005;23(5):515-522. PubMed ID: 16194999 doi:10.1080/02640410410001729928 